\title{
Standaardregelingen en Algemene voorwaarden
}

\author{
Een nieuw wettelijk fenomeen
}

Mr. R. H. Stutterheim

\section{De grondwet voor de contractsvrijheid}

Bij het naderen van de datum van de invoering van de boeken 3, 5 en 6 NBW is het goed dat de praktijk zich realiseert, dat per 1 januari 1992 niet het recht verandert doch de wet en zelfs ten aanzien van die verandering kan men niet stellen dat er sprake is van een principiële inhoudelijke herziening van het vermogensrecht. Deze geruststelling neemt echter niet weg dat de praktijk zich evenzeer dient te realiseren, dat in het nieuwe vermogensrecht een aantal rechtspolitieke tendensen worden gecodificeerd die in de afgelopen decennia al zichtbaar waren in de rechtspraak. Eén daarvan - en het zal niemand verbazen die de rechtspraak heeft gevolgd - is ongetwijfeld de grotere bescherming van de 'zwakkere partij' in het economisch verkeer.

Beter dan zijn voorganger uit 1838 toont de huidige wetgever het inzicht dat de formele juridische gelijkheid van partijen op economisch terrein de oorzaak kan zijn van het legitimeren van zeer frequent voorkomende ernstige ongelijkheden in het economisch maatschappelijk verkeer. $\mathrm{Er}$ is geen terrein in het nieuwe vermogensrecht waar dit inzicht helderder tot uitdrukking komt dan in de wetgeving ter zake van de standaardregeling (artikel 6:214) en van de algemene voorwaarden (artikel 6:231 t/m 247). De wetgever raakt met deze beschermende regeling een kernpunt in het vermogensrecht en daarmee één van de pijlers van de kapitalistische vrije marktecono- mie: de contractsvrijheid. Ook dat zal niemand verbazen. Immers, alleen in een vrije markteconomie in ongeciviliseerde vorm is het rechtens acceptabel het vel over de oren te halen van de economisch zwakkere partij. Modern management heeft meer oog voor de gerechtvaardigde belangen van de wederpartij, de onderlinge verwevenheid van economische belangen op de markt, het tempo waarin winstmaximalisatie kan plaatsvinden en voor de maatschappelijke en economische kosten van procedures over onredelijke bedingen. De wetgever NBW sluit aan bij deze maatschappelijke ontwikkeling maar is tevens richtinggevend voor hen die de aansluiting op deze ontwikkelingen hebben gemist.

Het zijn immers vooral de 'die-hards' van de absolute contractsvrijheid tot wie zich deze nieuwe wetgeving richt. Anderen hebben al langer begrepen dat de contractsvrijheid een relatieve waarde is, zoals elke waarde: afhankelijk van de waardering van tal van omstandigheden waarin die waarde wordt geoperationaliseerd. Absolute vrijheid te contracteren is in een moderne economie ondenkbaar: om te overleven als persoon of rechtspersoon moet men immers contracten sluiten. Maar ook de vrije keuze van de contractspartners blijkt vaak een illusie: de (semi)overheid, netwerken van multinationals of grootwinkelbedrijven en dergelijke zijn in de

Mr. R. H. Stutterheim is universitair docent verbonden aan de Juridische Faculteit van de Universiteit van Amsterdam. Hij publiceerde in het tijdschrift Rechtshulp, het NJB en het Tijdschrift voor Consumentenrecht. 


\section{MAB}

meeste gevallen de contractspartner in de strijd om het dagelijks bestaan. En men zou kunnen opmerken, wat doet het er toe dat men niet in volledige vrijheid de contractspartner kan uitkiezen, het gaat uiteindelijk niet om een huwelijk. Mits de produkten en diensten die worden aangeboden kwalitatief van niveau zijn, de prijzen redelijk zijn en de markt voor ieder toegankelijk is, valt er meer dan voldoende te onderhandelen en te kiezen op de huidige markten van de geïndustrialiseerde landen en is ook deze vrijheid van relatieve waarde. Blijft uiteindelijk de vrijheid om zelf mede de inhoud van het contract te bepalen.

Contractsvrijheid in die zin opgevat, wordt zowel door de praktijk als door juristen als het meest essentieel gezien. Dat is ook wel begrijpelijk, want als de maatschappelijke situatie zo is, dat men moet contracteren om te overleven en daarbij veelal niet vrij een contractspartner kan uitkiezen, dan lijkt het van het grootste belang dat men in elk geval de inhoud van het contract zelf (mede) kan bepalen.

Maar ook hier blijkt voor de practici hun eigen praktijk sterker dan de leer, want overeenkomsten worden veelal gesloten zonder dat de nauwkeurige inhoud van de overeenkomst vooraf door partijen wordt bedacht, uitgewerkt en schriftelijk vastgelegd. Bovendien zijn veel partijen daartoe ook niet in staat en is het telkenmale afzonderlijk bedenken, uitwerken en vastleggen praktisch onmogelijk; daarom laten partijen indien dat als opportuun wordt gezien - dat over aan professionele contractopstellers: aan juristen. En ook hier kan men opmerken: wat is er op tegen dat over te laten aan anderen, mits de inhoud maar redelijk en billijk is of zoals de wetgever het thans bij de algemene voorwaarden uitdrukt: niet onredelijk bezwarend is. De afspraak zelve is immers waar het maatschappelijk om gaat en de vaardigheden en de kwaliteiten die daarvoor noodzakelijk zijn, kunnen in alle vrijheid worden uitgeoefend en die vrijheid is van geheel andere aard dan de juridische contractsvrijheid.

Waar het in feite bij de juridische contractsvrijheid van partijen om gaat, is dat partijen naar aanleiding van hun afspraak buiten de wetgever om met elkaar regels mogen en kunnen vastleggen die op gelijke wijze binden als de regels van de wetge- ver: de wet. Maar evenzeer als dat een dwingende eis is voor de wetgever, geldt ook voor wat partijen vastleggen aan regels: alleen binding aan regels indien die regels in overeenstemming zijn met het recht, dus op zorgvuldige wijze tot stand zijn gekomen en redelijk en billijk zijn.

In dat licht moet men de wettelijke regeling zien van de standaardregeling en van de algemene voorwaarden: de wetgever geeft aan partijen de vrijheid bindende regels op te stellen, maar geeft tevens aan dat de vrijheid van partijen ten aanzien van regelgeving niet verder kan gaan dan zijn eigen vrijheid en werpt daarmee een dam op tegen hen die menen dat men vanuit de contractsvrijheid de vrijheid zou hebben bindende regels op te stellen waarvan de wijze van totstandkoming of de inhoud in strijd zijn met het recht. In dat opzicht vormen artikelen 6:214 en 6:231 e.v. mèt artikelen 6:2 en 6:248 de grondwet voor het juridisch vastleggen van afspraken. Men kan daarom spreken van een nieuw wettelijk fenomeen.

De wetgever erkent met deze grondwet principieel de vrijheid van partijen op het terrein van het vermogensrecht als eigen wetgever op te treden en juist daarom gaat het bij contractsvrijheid en juist die vrijheid is het meest essentiële en onderscheidende kenmerk van het privaatrecht.

\section{De standaardregeling}

2.1 Achtergronden, doel en strekking, toepasselijkheid

Meijers heeft de standaardregeling ontworpen als een middel tegen onbillijke bevoordeling en machtsposities in algemene voorwaarden van één der partijen. 'De middelen die onder het geldende wetboek de rechter ten dienste staan om uitwassen op dit gebied tegen te gaan, hebben weinig bevrediging kunnen schenken', zo meldt de toelichting bij 6.5.1.2.-3.

Eind jaren zeventig kwam men onder invloed van onder andere de adviezen van de Commissie voor Consumentenaangelegenheden van de SER (1978), de Nederlandse Juristen Vereniging (1979) en de regelingen in het buitenland tot de conclusie dat er een aparte en uitvoerige wettelijke regeling van de algemene voorwaarden 


\section{MAB}

moest komen en daarmee scheidde de regeling van de standaardregeling (6.5.1.2) zich af van die van de algemene voorwaarden (6.5.1.3).

Met deze afscheiding werden doel en strekking van de standaardregeling principieel gewijzigd. De standaardregeling werd een middel voor het beroeps- en bedriffsleven om hun overeenkomsten te regelen door middel van wettelijke regelingen van aanvullend recht. Deze delegatie van wetgeving komt tegemoet aan de huidige eisen ten aanzien van zelfregulering en past in een tijd van een terugtredende wetgever. Anderzijds doet de regeling ook denken aan de keuren van de gilden in de Middeleeuwen.

De standaardregeling kan van toepassing worden verklaard voor bijzondere soorten van overeenkomsten die door een bepaalde bedrijfstak of beroepsgroep worden gesloten, waarbij men kan denken aan specifieke verzekeringspolissen, vervoersovereenkomsten, huurovereenkomsten enzovoort. De bijzondere overeenkomsten èn de bepaalde bedrijfstak of beroepsgroep worden bij algemene maatregel van bestuur aangewezen. Deze dubbele begrenzing van de standaardregeling - naar bijzondere soorten van overeenkomsten èn naar een bepaalde bedrijfstak of beroepsgroep - zal ongetwijfeld gezien de branchevervaging en de mogelijkheid dat op dezelfde bijzondere overeenkomst verschillende standaardregelingen van toepassing kunnen zijn, afbakeningsproblemen gaan geven.

De standaardregeling is van rechtswege van toepassing, er is immers sprake van een wet in materiële zin krachtens delegatie door de formele wetgever.

\subsection{Totstandkoming}

Essentieel bij de totstandkoming, in feite de grondgedachte van de standaardregeling, is het overleg tussen de rechtstreeks belanghebbenden. Zij vormen als het ware het informele parlement van de standaardregeling: de Commissie Standaardregelingen (artikel 6:214 lid 2). De commissie wordt benoemd door de minister van Justitie en bestaat voor tenminste twee derde uit leden die worden voorgedragen door representa- tieve organisaties van hen die een bedrijf of beroep uitoefenen en van hen die hun wederpartij zijn.

Daarnaast kan de minister ook onafhankelijke deskundigen en niet-rechtstreeks betrokkenen benoemen; de inrichting en de werkwijze van dit mini-parlement zijn vastgelegd in de Wet commissie standaardregelingen (Stb. 1989, no. 567). Op deze wijze hoopt men dat een betere afweging van de betrokken belangen èn het algemeen belang zal plaatsvinden dan bij de totstandkoming van algemene voorwaarden het geval is. De door de minister van Justitie goedgekeurde standaardregelingen moeten worden gepubliceerd in de Nederlandse Staatscourant (artikel 6:214 lid 3).

\subsection{Afwijkingen van wettelijke bepalingen}

Standaardregelingen bevatten aanvullend recht, afwijkingen van dwingend recht zijn niet mogelijk, tenzij uit de wettelijke bepalingen iets anders voortvloeit, zoals het geval is bij artikel 6 lid 1 Boek 7 (dwingend recht bij de consumentenkoop), zie artikel 6:214 lid 4. Als middel tegen onereuze algemene voorwaarden kunnen zij dus niet dienen. Toch kunnen zij op indirecte wijze het gebruik van onredelijk bezwarende bedingen in algemene voorwaarden beperken door als vormvereiste voor het afwijken van een standaardregeling te eisen dat dit niet kan geschieden door enkele verwijzing naar algemene voorwaarden (artikel 6:214 lid 5). Bovendien zullen afwijkingen van standaardregelingen bij eenzijdig vastgestelde algemene voorwaarden sneller als onredelijk bezwarend aangemerkt worden. Ook de mogelijkheid van reflexwerking van standaardregelingen naar andere overeenkomsten die worden getoetst aan artikel 6:231 e.v., 6:248 lid 2 en $6: 258$, ligt voor de hand. Uit de aard van de standaardregeling vloeit echter voort, dat zij niet kunnen worden getoetst aan de wettelijke regeling van de algemene voorwaarden (bijvoorbeeld aan het criterium 'onredelijk bezwarend' of aan de zogenaamde zwarte en grijze lijsten), maar vanzelfsprekend wèl aan artikel 6:248 lid 2 en 258 . En ook bij die toetsing zal sprake kunnen zijn van reflexwerking, namelijk van de zwarte en grijze lijsten. 


\section{MAB}

\subsection{Betekenis voor de praktijk}

In de parlementaire geschiedenis en in de literatuur worden de voordelen van de standaardregeling ten opzichte van een regeling bij algemene voorwaarden benadrukt. Immers, het gaat om wetgeving in materiële zin zodat toetsing in cassatie minder problemen zou geven, ze zijn van rechtswege van toepassing, worden niet eenzijdig vastgesteld en worden beter bekendgemaakt.

Vooronderstelling bij al deze voordelen is wel dat de representatieve organisaties van belanghebbenden bereid zijn tot het overleg dat noodzakelijk is voor de totstandkoming van een standaardregeling en dat wordt geregeld door de algemene maatregelen van bestuur (artikel 6:214 lid 1), de minister van Justitie (artikel 6:214 lid 2) en de Wet commissie standaardregeling. De ervaring met het veel informelere overleg tussen belanghebbenden over algemene voorwaarden zoals wij dit al lang kennen in het kader van de oprichting van geschillencommissies in het Consumentenrecht (Erkennings- en Subsidiëringsregeling Commissies consumentenklachten 26-111975), is niet onverdeeld positief te noemen. Anders dan in het arbeidsrecht, bestaat er bij de Nederlandse ondernemer in bedrijf en beroep nog altijd een aarzeling om met representatieve organisaties van de wederpartij als afnemer van diensten en produkten te overleggen bij de vaststelling van algemene voorwaarden; het moderne management zoals hierboven aangeduid is zeker niet alom aanwezig. Maar stel dat de bereidheid tot overleg er wèl is, waarom zou men dan gelet op de nieuwe wettelijke regeling van de algemene voorwaarden kiezen voor de veel formelere regeling van overleg, vaststelling en wijziging bij de standaardregeling? Ik vermoed dat het Nederlandse bedrijfs- en beroepsleven in een fase is, waarbij men overleg over algemene voorwaarden langzamerhand als goed management gaat zien en dat vereist voor velen al een grote omschakeling. Te verwachten is daarom, dat de commissies standaardregeling voorlopig niet of nauwelijks tot ontwikkeling zullen komen. Denkbaar is echter dat bij toename van de internationale concurrentie door de voltooiing van de Europese markt in 1992 die situatie verandert.

\section{Algemene voorwaarden}

\subsection{Inleiding}

De beroemde en beruchte kleine lettertjes die zo vaak voor onaangename verrassingen zorgen, zijn een ieder bekend. Het gaat dan om schriftelijke bedingen die zonder onderhandelingen tussen partijen worden opgenomen in een overeenkomst. Soms vindt bij de totstandkoming van algemene voorwaarden overleg plaats met de wederpartij of hun organisaties, bijvoorbeeld de Consumentenbond. De overgrote meerderheid van algemene voorwaarden wordt echter nog altijd eenzijdig opgesteld. Essentieel voor de totstandkoming van overeenkomsten is echter de wederzijdse wilsovereenstemming of toestemming van partijen met betrekking tot de inhoud van hun overeenkomst. Is deze wilsovereenstemming niet aanwezig, dan is de overeenkomst in de meeste gevallen nietig. Van deze wilsovereenstemming is bij algemene voorwaarden niet of nauwelijks sprake; de wederpartij kent of leest deze voorwaarden meestal zelfs niet. Omdat de algemene voorwaarden in hoofdzaak eenzijdig worden opgesteld, zeer veel voorkomen en de wilsovereenstemming meestal ontbreekt, zijn problemen ontstaan en met name omdat allerlei bedingen worden opgenomen die alleen rekening houden met het belang van de opsteller. Aangezien de wederpartij daaraan niets kan veranderen en er vaak geen uitwijkmogelijkheden zijn, bevindt de wederpartij zich daardoor in een dwangpositie.

Aan de andere kant wordt algemeen erkend, dat algemene voorwaarden in het maatschappelijk verkeer absoluut noodzakelijk zijn. Het functioneren van zeer veel maatschappelijke organisaties is gelet op de noodzaak van besparing van tijd en kosten, het intern functioneren van de organisatie en de eenheid van het rechtsverkeer, afhankelijk van het bestaan van algemene voorwaarden. Individueel contracteren is in zeer veel gevallen niet meer mogelijk.

Met betrekking tot de problemen rond de algemene voorwaarden staan twee vragen centraal: zijn de algemene voorwaarden van toepassing? en, zo ja, is de inhoud van de algemene voorwaarden ook geldig? 


\section{MAB}

Rond de eerste vraag, waar het gaat om de vraag naar wilsovereenstemming tussen partijen, is in de lagere rechtspraak een eindeloze en warrige casuiistiek ontstaan over de kenbaarheid van de algemene voorwaarden, waarbij opvalt dat de rechtspraak in steeds sterkere mate neigde naar toepasselijkheid. Ook de Hoge Raad heeft zich verschillende keren over deze vraag moeten buigen. Enige beperking ten aanzien van de toepasselijkheid werd aangebracht in Towel-Janson (HR 9 december 1977, NJ '78, 187): de opvatting dat, indien in een brief waarin de overeenkomst is vastgelegd een verwijzing voorkomt naar algemene voorwaarden dan 'dient te worden aangenomen dat die voorwaarden op de overeenkomst van toepassing zijn, tenzij komt vast te staan dat partijen de toepasselijkheid van die voorwaarden hebben uitgesloten' werd toen verworpen ( $\mathrm{Vgl}$. ook recentelijk HR 15 maart 1991, RvdW '91, no. 78: Van Lente \& Visscher-Ossfloor Tapijtfabrieken.) In Holleman-De Klerk (HR 20 november 1981, NJ '82, 517) werd aangenomen dat voor het toestemmen in algemene voorwaarden bij het sluiten van een overeenkomst in het handelsverkeer geen andere eisen gelden dan de gewone. Echter, als eenmaal vaststaat dat algemene voorwaarden van toepassing zijn, wil dat nog niet zeggen dat de gebruiker daarop te allen tijde een beroep kan doen.

Aan de hand van de tweede vraag is een rijke jurisprudentie ontstaan waarbij toetsing aan de goede trouw centraal staat. De standaardarresten zijn hier Saladin-HBU (HR 19 mei 1967, NJ '67, 261) en Pseudovogelpest (HR 20 februari 1976, NJ '76, 486). (Vgl. recentelijk HR 8 maart 1991, RvdW '91, no. 72: Staalgri De Kleijn-Leendert Van der Ende). Overigens moet worden opgemerkt dat het NBW geen regels bevat omtrent de uitleg van overeenkomsten, zodat de oude rechtspraak op dat punt van belang blijft (bijvoorbeeld Ram-Matser, HR 1 juli 1977, NJ '78, 125 en Ermes-Haviltex, HR 13 maart 1981, NJ '81, 635).

De in de rechtspraak naar voren gekomen onzekerheden met betrekking tot de toepasselijkheid en de gelding van algemene voorwaarden zijn in een modern rechtsverkeer onaanvaardbaar, vandaar dat een wettelijke regeling onontkoombaar was en niet alleen in Nederland zoals moge blijken uit de Richtlijn van de EG inzake oneerlijke bedingen in consumentenovereenkomsten ( 3 september 1990, CON (90) 322 def.). Het doel van afdeling 6.5.3 is:

- het bieden van rechtszekerheid ten aanzien van de toepasselijkheid en de gelding van algemene voorwaarden;

- de versterking van de rechterlijke controle op de algemene voorwaarden;

- het stimuleren van overleg tussen belanghebbenden over de inhoud van algemene voorwaarden.

De nieuwe regeling van de algemene voorwaarden in het NBW berust op vier pijlers:

1 De gebondenheid aan algemene voorwaarden, ook als gebruiker begreep of moest begrijpen dat zijn wederpartij de inhoud daarvan niet kende (artikel 6:232).

2 De vernietigingsgronden in geval van 'onredelijk bezwarend' zijn of van het niet bieden van een redelijke mogelijkheid van de algemene voorwaarden kennis te nemen (artikel 6:233).

3 De bijzondere bescherming van consumenten door de zogenaamde zwarte en grijze lijsten (artikel 6:236 en 237).

4 De collectieve actie van belangenorganisaties (artikel 6:240).

\subsection{De toepasselijkheid}

Indien vaststaat dat het gaat om schriftelijke bedingen die zijn opgesteld teneinde in een aantal overeenkomsten te worden opgenomen en het niet gaat om bedingen die de kern van de prestatie weergeven (prijs, soort, hoeveelheid) èn tevens vaststaat dat er sprake is van een geldig tot stand gekomen overeenkomst (zie artikel 3:33 e.v. jo artikel 6:217 e.v.), dan eerst is de regeling van de algemene voorwaarden van toepassing, ook als de gebruiker weet dat zijn wederpartij de inhoud niet kent (artikel 6:231 en 232). Uitgangspunt is dus de toepasselijkheid van de algemene voorwaarden en daarmee probeert de wetgever de oeverloze discussie over dat onderwerp af te snijden. Men bedenke dat de regeling ook van 


\section{MAB}

toepassing is op door de overheid gebruikte algemene voorwaarden, alleen materiële wetgeving valt buiten het bereik van de regeling (zie hiervoor). De afdeling 6.5.3 is hoofdzakelijk van dwingend recht (artikel 6:246) maar is niet van toepassing op (collectieve) arbeidsovereenkomsten (artikel 6:245). Op een overeenkomst tussen in Nederland gevestigde ondernemers en op overeenkomsten tussen in Nederland wonende consumenten en ondernemers is de regeling altijd van toepassing, ongeacht het recht dat de overeenkomst beheerst (artikel 6:247 lid 1 en lid 4).

Belangrijk is te bedenken dat de regeling de consumentenbescherming niet voorop stelt: ondernemers worden in gelijke mate beschermd. Gezien de achtergronden van de regeling is het ook begrijpelijk dat grote ondernemingen de bescherming niet behoeven: zij kunnen geen beroep doen op vernietigingsgronden in de artikelen 6:233 en 6:234 (zie artikel 6:235). Overigens is aan de ondernemers nog enige tijd gegund hun algemene voorwaarden aan te passen aan de nieuwe wetgeving. Op algemene voorwaarden die per 1 januari 1992 reeds werden gebruikt, is de afdeling 6.5.3 pas per 1 januari 1993 toepasselijk; op algemene voorwaarden die na 1 januari 1992 voor het eerst worden gebruikt is de regeling onmiddellijk van toepassing (artikel 191 Overgangswet NBW).

\subsection{De vernietigingsgronden}

Voorop staat de vernietiging wegens het 'onredelijk bezwarend' zijn, hetgeen door middel van een buitengerechtelijke verklaring kan worden ingeroepen. Bij de vernietiging spelen de aard en de overige inhoud van de overeenkomst, de wijze waarop de voorwaarden tot stand zijn gekomen, de wederzijdse kenbare belangen en de overige omstandigheden van het geval, een belangrijke rol. We herkennen in deze opsomming het HBUen Pseudovogelpestarrest. En inderdaad, het criterium 'onredelijk bezwarend' in artikel 6:233a functioneert bij de algemene voorwaarden als het ware als een dochtermaatschappij van de moedermaatschappii 'redelijkheid en billijkheid' (artikel 6:2 lid 2), met dien verstande dat het criterium 'onredelijk bezwarend' ook een vernietigingsgrond is bij de totstandkoming van de overeen- komst, terwijl de moedermaatschappij alleen opereert bij de uitvoering van de overeenkomst. (Zie bijdrage van Abas). Dit houdt het gevaar in dat de dochtermaatschappij ('onredelijk bezwarend') de leerstukken omtrent dwaling, bedrog en misbruik van omstandigheden opslokt. (Zie hierover: $P$. van Schilfgaarde in zijn noot bij het arrest Centrale Antenne HR 25 april 1986, NJ 1986, 714, AA XXXV, p. $622 \mathrm{lk}$ ).

Opstellers die algemene voorwaarden geheel eenzijdig vaststellen zullen terdege met dit criterium rekening moeten houden, omdat de in de praktijk bestaande neiging alleen oog te hebben voor het eigen belang een rol gaat spelen bij 'de wijze waarop de voorwaarden zijn tot stand gekomen' en 'de wederzijdse kenbare belangen'. De 'straf' bij onredelijk bezwarend bedingen is vernietigbaarheid en een beroep op coulance helpt niet (vgl. Botman-Van Haaster, HR 23 maart 1990, NJ '91, 214), terwijl, gelet op de ervaringen in Duitsland, te verwachten is dat de rechter conversie (artikel 3:42) niet snel zal toepassen omdat de verantwoordelijkheid voor de formulering van correcte bedingen nu eenmaal allereerst bij de gebruiker ligt.

Niet minder belangrijk is echter de tweede vernietigingsgrond: het geen kennis hebben kunnen nemen van de algemene voorwaarden (artikel 6:233b). De wetgever werkt dit uit in artikel 6:234. Van een redelijke mogelijkheid om van algemene voorwaarden kennis te nemen, is sprake indien:

a de algemene voorwaarden voor of bij het sluiten van de overeenkomst ter hand zijn gesteld, of,

$\mathrm{b}$ indien terhandstelling redelijkerwijs niet mogelijk is, voor het sluiten van de overeenkomst bekend is gemaakt dat de algemene voorwaarden ter inzage liggen bij de gebruiker of bij de Kamer van Koophandel of een griffie van een gerecht èn dat zij op verzoek zullen worden toegezonden, tenzij dat redelijkerwijze niet mogelijk is.

De gebruiker moet dus vòòr het sluiten van de overeenkomst het initiatief nemen; terhandstelling na de totstandkoming van de overeenkomst is zinloos, terwijl ook terhandstelling zonder de 


\section{MAB}

mogelijkheid te bieden kennis te nemen van de inhoud niet relevant is. Bij uitzondering kan terhandstelling achterwege blijven en kunnen de algemene voorwaarden ter inzage worden gelegd.

Deze informatieplicht van de gebruiker zal in de praktijk nauwkeurig moeten worden nageleefd en vereist bij veel gebruikers een concrete wijziging in het optreden naar de wederpartij. Zonder enige twijfel zal dit vereiste een bron gaan vormen voor veel rechtspraak, omdat niet gezegd kan worden dat deze informatieplicht leeft bij de gebruikers van algemene voorwaarden; gebruikers doen er daarom verstandig aan uitdrukkelijk instructies op te stellen voor de bekendmaking van hun algemene voorwaarden.

\subsection{De zwarte en grijze lijsten}

Teneinde de doelstelling van de rechtszekerheid vorm te geven en het criterium 'onredelijk bezwarend' te concretiseren, wordt uit het oogpunt van doelmatigheid en rechtvaardigheid een wettelijke opsomming gegeven van bedingen die op de voorhand voor vernietiging in aanmerking komen: de zwarte en grijze lijsten van artikel 6:236 en 6:237. Deze bescherming geldt echter alleen in overeenkomsten met consumenten, aangezien de werking van de in deze lijsten genoemde bedingen in andere overeenkomsten niet is te overzien vanwege de veelsoortigheid van allerlei commerciële belangen.

De zwarte lijst geeft een checklist van bedingen die altijd vernietigbaar zijn, veertien in aantal. De grijze lijst omvat veertien bedingen waarvan vermoed wordt dat zij onredelijk bezwarend zijn, het bewijs van het tegendeel rust op de gebruiker. Een opsomming van deze bedingen en een exercitie in de contracten waarin zij voorkomen, is in het kader van dit artikel niet zinvol en heeft bovendien een te abstract karakter. De onderwerpen zijn zeer gevarieerd en betreffen onder andere beëindiging, bewijs, domiciliekeuze, exoneratie, geschillenbeslechting, nakoming, ontbinding, prijsverhoging, verjaring, verlenging, verrekening, vormvoorschriften, wanprestatie.

ledere gebruiker van algemene voorwaarden doet er goed aan zijn voorwaarden te toetsen aan deze lijsten. Voor een dergelijke controle is enige fantasie en vernuft een vereiste omdat de formulering van veel bedingen in bestaande algemene voorwaarden niet exact zullen overeenkomen met de tekst van de zwarte en grijze lijst maar naar hun inhoud evenzeer vernietigbaar zijn. Veel gebruikers zullen voor het eerst sinds jaren hun eigen voorwaarden weer eens lezen en zij zullen daarbij niet alleen rekening moeten houden met de zwarte en grijze lijsten maar ook met het nieuwe dwingend recht als bijvoorbeeld bij de consumentenverkoop. (Zie de bijdrage van Oly). Tevens kan men dan van de gelegenheid gebruik maken om dat wat overbodig is of dat wat al in het NBW wordt geregeld in aanvullend recht, te verwijderen of aan te passen.

Deze nationale opschoning zal ertoe moeten leiden dat procedures over de inhoud van algemene voorwaarden afnemen, maar bovendien wordt zodoende de kans verkleind dat in het geval dat de voorwaarden wegens niet nakomen van de informatieplicht niet van toepassing zijn, de gebruiker daar ernstig nadeel van ondervindt. Voorwaar een boeiende taak voor het management!

\subsection{De collectieve actie}

In het kader van de beperking van procedures over algemene voorwaarden past ook de regeling van het collectieve actierecht van belangenorganisaties (artikel 6:240). Een andere belangrijke doelstelling die hiermee wordt gerealiseerd, is dat de gebruikers en hun wederpartijen gestimuleerd worden tot onderhandelingen. Op zichzelf moet het vreemd worden genoemd, dat in het algemeen het eenzijdig vaststellen van voorwaarden bij het aanbod van arbeid in Nederland volstrekt ongebruikelijk is, terwijl dit anderzijds bij het aanbod van goederen en diensten regel is. Weliswaar is deze situatie, onder andere op het terrein van het consumentenrecht, aan het veranderen, maar wettelijke stimulansen kunnen niet worden gemist, zeker nu het Voorontwerp Vorderingsrecht Belangenorganisaties contractsacties uitsluit (zie hierover K. Rozemond, in Rechthulp 1989, no. 4). Op vordering van rechtspersonen met volledige rechtsbevoegdheid die ten doel hebben de behartiging van belangen van personen die een beroep of bedrijf uitoefenen of van 


\section{MAB}

eindgebruikers van niet voor een beroep of bedrijf bestemde goederen en diensten - kortom organisaties van ondernemers of consumenten - , kunnen bedingen in algemene voorwaarden onredelijk bezwarend worden verklaard op basis van de artikelen 6:233a, 236, 237 of omdat een beding in strijd is met een dwingende wetsbepaling (artikel 6:240 lid 1 en 3 ).

Zowel tegen de gebruiker als tegen een brancheorganisatie die de algemene voorwaarden voor de gebruiker opstelt of het gebruik ervan voorschrijft, kan de vordering worden ingesteld (artikel 6:240 lid 2).

In artikel 6:240 lid 4 brengt de wetgever zijn wens naar onderhandelingen tussen belanghebbenden naar voren: de eiser is niet ontvankelijk als niet eerst geprobeerd is om in onderling overleg tot een aanpassing of regeling te komen. Een termijn van zes maanden na schriftelijke kennisgeving van de bezwaren is in elk geval voldoende om ontvankelijk te zijn, tenzij de eiser met het gebruik van de algemene voorwaarden heeft ingestemd (zie artikel 6:240 lid 5, vandaar dat de consumentenorganisaties in het met hen gevoerde overleg op dat laatste punt altijd een voorbehoud maken). Het door de wetgever bedoelde overleg vindt thans hoofdzakelijk plaats in de Commissie Consumentenaangelegenheden (CCA) van de SER en gaat bijvoorbeeld altijd vooraf aan het vaststellen van een erkende geschillencommissie bij de Stichting Consumentenklachten in Den Haag.

Opmerkelijk is daarbij, dat het bijna uitsluitend de Consumentenbond en Konsumenten Kontakt zijn die dit overleg met de ondernemers voeren. Van een specialisatie en decentralisatie van belangenbehartiging, zoals die bekend is bij het arbeidsvoorwaardenoverleg en in de brancheorganisaties, is bij consumenten nog nauwelijks sprake. Dit centreren van het overleg bij slechts twee organisaties kan nadelig zijn voor de consumenten, zodat te wensen ware dat er belangenorganisaties gaan ontstaan die zich specialiseren op deelterreinen: energieverbruikers, verzekeringen, bankrekeninghouders en dergelijke (vgl. bijvoorbeeld de Vereniging Eigen Huis). In dit verband dient men te waken voor het ontstaan van een niet gedifferentieerde, niet gespecialiseerde centraal geleide belangenbehartiging waarbij de leden slechts een zeer geringe eigen rol spelen.

De toetsing van algemene voorwaarden binnen de procedure van artikel 6:240 - die in tegenstelling tot de concrete toetsing van artikel 6:233a ook wel abstracte toetsing wordt genoemd vindt plaats door een bijzondere rechter: het Hof Den Haag (art. 6:241 lid 1). De uitspraak dat een beding onredelijk bezwarend is, kan worden voorzien van nevenveroordelingen - eventueel onder dwangsom - als: een verbod van het gebruik van het beding, een gebod om een aanbeveling tot het gebruik van het beding te herroepen of een veroordeling tot openbaar maken van de uitspraak (art. 6:241 lid 3). Te verwachten is, dat aan de declaratoire uitspraak vaak een verbod zal worden gekoppeld.

\subsection{De beknelde tussenschakel}

Indien een beding in de overeenkomst tussen bijvoorbeeld een detaillist en een consument in een concrete of abstracte toetsing onredelijk bezwarend is verklaard, kan dat vervelende gevolgen hebben voor de detaillist. Vaak geven detaillisten de bedingen die door hun voorschakel (de producent of leverancier) aan hen worden opgelegd, door aan de consument. Echter, het onredelijk bezwarend zijn van het beding in de relatie detaillist-consument betekent nog niet dat datzelfde beding onredelijk bezwarend is in de relatie tussen de detaillist en zijn voorschakel (denk bijvoorbeeld aan exoneratieclausules).

De detaillist wordt nu het slachtoffer van de vernietiging van het beding, terwijl hij slechts als doorgeefluik van zijn voorschakel optreedt. Artikel 6:244 voorkomt dat, mits er een nauwe samenhang is tussen het beding dat is vernietigd en het beding dat door de voorschakel is opgelegd. De regeling is zodanig dat het risico van vernietiging uiteindelijk terecht komt bij degene die de auteur is van het beding (artikel 6:244 lid 4). Deze regeling benadrukt nogmaals de verantwoordelijkheid van degene die algemene voorwaarden opstelt èn laat zien dat het in afdeling 6.5.3 niet alleen gaat om consumentenbescherming. Een vergelijkbare regeling treffen we aan in artikel 7:25 waar het regres van de verkoper op zijn voorschakel is geregeld. De wetgever toont 


\section{MAB}

hier inzicht in de nauwe relaties tussen de verschillende markten.

\section{Tot slot}

Het is bekend, dat het wetsontwerp inzake algemene voorwaarden (1981) veel weerstanden in het bedrijfsleven heeft opgeroepen. Met moeite overleefde het ontwerp de zogenaamde 'operatie stofkam' en ontsnapte het aan de dereguleringsdrift van de commissie Van der Grinten. Bekend is ook dat het ontwerp uiteindelijk is gered door minister Korthals Altes, staatssecretaris Van Zeil en Hartkamp tijdens een diner met Van der Grinten in restaurant Royal in Den Haag: 'Hartkamp moet het debat op punten gewonnen hebben, want sindsdien verdedigde de bewindsman als zijn standpunt dat 'de onredelijke hinder voor het bedrijfsleven onvoldoende geconcretiseerd was en niet opwoog tegen het te beschermen belang van de consument' (UCV, p. 19, dk)'. ${ }^{1}$ Op het laatste ogenblik leek het ontwerp nog te stranden op 1 oktober 1984 in de Vaste commissie voor Justitie, hetgeen de voorpagina haalde van de Telegraaf en onder de misleidende kop 'WD en CDA eisen andere consumentenwet' de dag erna in de Volkskrant werd gepubliceerd en dat ging ook de verantwoordelijke bewindslieden van CDA en WD te ver.

Van groot belang is zeker geweest het feit dat een vergelijkbare wettelijke regeling al lang gold in Duitsland (1976), Engeland (1977) en Frankrijk (1978) en daar van ondernemerszijde werd geaccepteerd. Overziet men achteraf de geschiedenis van de totstandkoming van de standaardregeling en de algemene voorwaarden, dan zijn wellicht koudwatervrees - en misschien ook een wat beperkte blik op de vrijheid afspraken te maken en de juridische contractsvrijheid in de Europese markt - , de oorzaak geweest van zoveel commotie. De wetgever bleek uiteindelijk, gezien de Richtlijnen van de EG en het tot stand komen van een Europese markt, een vooruitziende blik te hebben.

De operatie stofkam en de deregulering ten aanzien van de algemene voorwaarden kan eerst nu en wel door het bedrijfsleven zèlf - op zinvolle en verantwoorde wijze plaatsvinden!

\section{Noot}

1 Zie Kwartaalbericht Nieuw BW 1988/4 p. 118 lk. 